it also has the advantage that it brings together for ready reference a series of articles dealing with one of the most important, and at the present time one of the most rapidly developing branches of medicine.

Pulmonary tuberculosis is the subject of seven of the nineteen articles in this volume, the particular aspects of the subject treated being early diagnosis, pulmonary tuberculosis in young adults, the heart in pulmonary tuberculosis, senile phthisis, the employment of simultaneous bilateral artificial pneumothorax and the care of arrested pulmonary tuberculosis. Thoracoplasty, pleurisy with effusion and spontaneous pneumothorax are other topics which come under review.

As an appendix there is supplied some, but in our opinion rather scanty, statistical information regarding the cases treated during the year at the hospital. In view of the wealth of clinical material which passes through this most important institution it seems a pity that it is not submitted to a more detailed analysis since we feel sure that in this way much important information would be obtained and rendered available for reference.

\section{THORACIC SURGERY.}

A revised and abridged edition of Sauerbruch's Die Chirurgie der Brustorgane.

By. Ferdinand Sauerbruch and Laurence O'Shaughnessy. Edward Arnold \& Co. London. 1937. Price 50 - net.

One of the most important and far reaching developments of surgery in recent years is the surgery of the chest. Surgical intervention in the chest was made possible with the introduction of differential pressure anæsthesia in 1904. One of the pioneers in this branch of surgery is Ferdinand Sauerbruch who reviewed his extensive experience in his work-Die Chirurgie der Brustorgane. We welcome the appearance of this work in concise English form to which is added a résumé of other significant contributions to the subject during the last ten years.

The first sections of the book are occupied with an excellent account of the function of the lungs, general diagnosis, general technique of thoracic surgery, the control of an open pneumothorax, the technique of thoracotomy and post-operative treatment.
There follows an excellent detailed account of the surgery of the various parts of the chest.

With regard to certain details in the book we feel that the modern concept of diverticula of the cesophagus based on recent careful work could have been incorporated with advantage to the exclusion of the timehonoured classification of traction and pressure diverticula. We notice that the authors give but little attention to the use of irradiation therapy in the treatment of cancer of the csophagus. A notable advance in the treatment of this disease has been the development of a technique whereby the œsophageal growth is efficiently irradiated by high voltage $\mathrm{X}$-rays. The technique of œsophageal resection is considered in detail but we feel that more work is required in this field before resection of the œesophagus becomes a really practical proposition.

We welcome the excellent account of the surgical treatment of cardiac ischæmia which is given in the appendix. O'Shaughnessy is to be congratulated on the contribution which he has made to the surgery of the heart.

The book is produced well with many excellent illustrations. An excellent bibliography is available at the end. This work should be in the possession, not only of the physician and surgeon interested especially in diseases of the chest but also of the general surgeon and the general practitioner.

\section{HEART DISEASE AND PREGNANCY.}

By CRighton Bramwell, M.A., M.D., F.R.C.P., and EDITH A. Longson, M.B., Ch.B., D.P.H. With a foreword by Sir Ewen Maclean, M.D., F.R.C.P., LLD., D.Sc., etc. Pp. 206 : 57 illustrations. Humphrey Milford, Oxford University Press. London. 1938. Price $8 / 6$ net.

This short and very readable monograph is written for general practitioners.

The clinical manifestations of those types of heart disease which affect young women are well described and cover a large part of the text.

The conclusions with regard to treatment and prognosis are based on a full investigation of a series of 350 cases of organic heart disease, all of whom were observed 
throughout labour and the puerperium. The after-histories of many have been subsequently followed up.

The figures and tables are simple and clear, and are of great assistance.

Chapter VII deals with prophylactic measures, therapeutic abortion, Cæsarean Section and induction of premature labour, and there is a reference to anæsthesia during labour. Due emphasis is laid on the importance of never interfering with pregnancy until heart failure has received adequate medical treatment. The authors stress the risk of therapeutic abortion after the end of the third month of pregnancy, and emphasize the advantages of Cæsarian Section over induction of premature labour, when termination of pregnancy in the later months is indicated. It is surprising to see radium or deep $\mathrm{X}$-ray therapy indicated as the method of choice for sterilization.

Chapters VIII and IX deal with prognosis. A comparison between the results obtained in those patients receiving adequate antenatal supervision and those admitted as urgencies, i.e. without comparable antenatal care, is strikingly in favour of the former.

It is interesting to note the confirmation of recorded observations that the combination of mitral stenosis and aortic incompetence do not add appreciably to the gravity of immediate prognosis. The authors do not attach as much importance to cardiac enlargement per se in immediate prognosis as other observers.

The surprising observation is made and figures given to confirm, that a history of repeated attacks of rheumatic fever in no way affects prognosis.

Although some attention is given to radiography under the heading of "Cardiac Enlargement," the importance of cardioscopic methods of examination and investigation in all cases referred to the cardiologist, has not been stressed.

Sir Ewen Maclean has written a foreword, and his statement that " the text comprises well-balanced discussions as to diagnosis, prognosis, and treatment, as well as vigorous opinions" is indeed an accurate observation.

This is a very useful book, and should appeal to general practitioner, cardiologist and obstetrician alike. It can be recommended without hesitation and should achieve a well deserved popularity.

\section{MODERN TREATMENT IN GENERAL PRACTICE.}

$A$ yearbook of diagnosis and treatment for the general practitioner : Vol. IV. 1938. By C. P. G. Wakeley, D.Sc., F.R.C.S.

Baillière, Tindall \& Cox. London. Price $10 / 6$ net.

This latest volume of this valuable series maintains the high standard set by the first three. There are fifty-two articles on very varied topics in which the subjects are discussed in a very practical fashion, so that the reader can fit them in to his own experience or add them thereto. Twenty of the articles come under a sub-head of Pitfalls in Diagnosis, in which abdominal conditions, childhood diseases, fractures, and lesions of the skin are very helpfully considered. While one can enjoy wholeheartedly articles like Whitfield's on nonspecific inflammation of the skin, Fraser on pain in the Iliac fossa, and Findlay on epigastric pain in childhood, highly specialised articles like those on chronic sinusitis, its treatment by radio-therapy; The prevention and treatment of influenza and pneumonia by means of ultra-violet light; and the fixation abscess in septicæmia, can not be assessed by the average general practitioner, and would seem to deserve some editorial comment for his guidance.

There are 28 plates in illustration of some of the articles.

\section{THE PHYSIOLOGY OF THE KIDNEY.}

By Prof. Homer W. Smith, A.B., Sc.D., M.S. Oxford University Press. 1937. Price 15/-.

It is some twenty years since Cushny wrote his memorable monograph on "The Secretion of Urine," the appearance of which gave a fresh outlook and renewed interest in the whole question of how the kidneys did their work. Cushny attempted to refute the vitalistic theory of urinary secretion and to explain the whole process on a mechanistic basis. Since then, however, an enormous amount of biochemical work has been done on the subject of urinary secretion and fresh evidence for or against. The vital or selective action of the tubules, either as an absorptive or as an excretory 